\title{
A Design of the Incentive and Restraint Mechanisms for Venture Capitalists in the Venture Funds of the Limited Partnership
}

\author{
Pingping Liu \\ Beijing Wuzi University \\ Beijing, China \\ pingpl@163.com
}

\author{
Chunsheng Jiang \\ Beijing Wuzi University \\ Beijing, China
}

\begin{abstract}
There is a principal-agent relationship between investors and fund managers - venture capitalists for the venture funds in the limited partnership. The compensation for the venture capitalists is mainly from the fund management fees and carried interests. For the venture capital funds in the different stages, the forms and degrees of compensation mechanism are also different because of the differences of venture capitalists and their environment, as well as some other factors. The thesis focuses on the effective incentive mechanism for the fund managers with funds in the newly founded stage as well as the stage of development, so that the quality and efficiency of the fund regulation can be improved.
\end{abstract}

Keywords-limited partnership; venture capitalists; principal-agent relationship; incentive and restraint mechanisms

\section{INTRODUCTION}

There is a principal-agent relationship between investors and fund managers - venture capitalists for the venture funds in the limited partnership. The requirements of venture capitalists for the residual claim of the investment income, reflecting the correspondence between risks and profits, plays an important part in the incentive mechanism. The risk compensation for venture capitalists is mainly from the fund management fees and the carried interests. The ratio to share the benefit under a different form of the funds is generally different. Meanwhile, the carried interest has to be realized on the basis of distributable profits made in the venture capital process, which has a practical significance in the incentive and restraint mechanisms for the venture capitalists (Sahlman, 1990). Investors can not take advantage of the board or some other systems to efficiently control and manage the fund managers according to their contracts. Moreover, the costs for investors to dismiss investment managers and the risks posed to losses are too high.

For the venture capital funds in the different stages of development, the forms and extents of the risk compensation mechanism should also be different because of the difference of venture capitalists and their environment, as well as the reputation and changes in the information asymmetry. The following statement illustrates, by analyzing the model, the incentive mechanisms for the risk funds in the newly founded stage as well as the stage of development, so as to establish the optimal contracts to reveal capital manage risk, and to improve the quality and efficiency of the fund regulation effectively.

\section{A DESIGN OF THE INCENTIVE ANNISMS FOR} THE FIRST-STAGE FUND

We assume that the venture capital firm raises two venture funds over a period of time, and the performance of the first-stage fund is known before the second-stage venture fund being raised. The first-stage fund has already been liquidated totally, and the two venture funds are completely independent. If fund investors are institutional investors, and the risks they are having are neutral. Venture capitalists are risk averse because of the lack of diversification of investment and wealth constraints.

The level of skills of venture capitalists $\eta$ (such as project selection, investment value, etc.) follows a normal distribution, namely $\eta \sim N\left(m_{0}, \sigma_{0}{ }^{2}\right)$, in which $\eta$ is public knowledge variable.

In the period of $\mathrm{t}$, the function of the fund income is

$$
\pi_{t}=\eta+e_{t}+\varepsilon_{t}
$$

In which, $e_{t}$ : the level of efforts made by venture capitalists in the period of $t$, which can not be observed by the investors. The choice of the level of efforts is private information

$\varepsilon_{t}$ : random error term subjecting to an independent normal distribution, namely $\varepsilon_{t} \sim N\left(0, \sigma_{\varepsilon}{ }^{2}\right)$

The reward function of venture capitalists is

$$
w_{t}\left(\pi_{t}\right)=f_{t}+v_{t} \pi_{t}
$$

in which, $w_{t}$ : the income received by venture capitalists during the period of $\mathrm{t}$

$f_{t}$ : the fixed reward achieved by venture capitalists 
$v_{t}$ : the proportion of income of the fund owned by venture capitalists

The cost of the efforts $c\left(e_{t}\right)$ made by venture capitalists, as public information, can be

obtained by investors. The function of the effort cost is convexity, $c^{\prime}(0)=0, c^{\prime}(\infty)=\infty, c^{\prime \prime}>0$ and meet the need of uniqueness of the equilibrium contracts.

According to Gompers \& Lerner (1999), the utility function of venture capitalists is

$$
U\left(w_{1}, w_{2} ; e_{1}, e_{2}\right)=-\exp \left(-r\left[\sum_{t=1}^{2} \delta^{t-1}\left[w_{t}-c\left(e_{t}\right)\right]\right]\right)
$$

in which, $r$ : the coefficient of risk aversion of venture capitalists

\section{$\delta$ : the constant discount rate}

According to the pre-established compensation contract in the venture funds, the remuneration of venture capitalists will be different. The venture funds investors can, by reference to some related information disclosed in the first-stage fund during the period of the second-stage fund being raised, make a assessment of the fund benefit and skills and effort of venture capitalists, so as to make further investment decisions.

Because of the complete symmetry of the information on venture capitalists, the bargaining strength of both sides are equal when they have a negotiation on the return of investment, which may reach Nash equilibrium, namely, the outcome of the negotiations between investors and venture capitalists on compensation contract subjects to Nash equilibrium. They share the current total utility.

$$
\begin{aligned}
& f_{1}\left(v_{1}\right)+v_{1} E\left(\pi_{1} \mid e_{1}\right)-C\left(e_{1}\right)=\frac{1}{2}\left[E\left(\pi_{1} \mid e_{1}\right)-C\left(e_{1}\right)\right] \\
& f_{2}\left(v_{2}\right)+v_{2} E\left(\pi_{2} \mid \pi_{1}, e_{1}, e_{2}\right)-C\left(e_{2}\right) \\
& =\frac{1}{2}\left[E\left(\pi_{2} \mid \pi_{1}, e_{1}, e_{2}\right)-C\left(e_{2}\right)\right]
\end{aligned}
$$

After observing the income of the first-stage fund, the investors take the effort level of venture capitalists for e1, and the level of their skills for $\mathrm{m} 1$, then:

$\hat{\eta}=m_{1}\left(\pi_{1}, e_{1}\right)=\frac{\sigma_{\varepsilon}{ }^{2} m_{0}+\sigma_{0}{ }^{2}\left(\pi_{1}-e_{1}\right)}{\sigma_{\varepsilon}{ }^{2}+\sigma_{0}{ }^{2}}$

$$
E\left(\pi_{1} \mid e_{1}\right)=m_{0}+e_{1}\left(v_{1}\right) \quad E\left(\pi_{2} \mid e_{1}, e_{2}, \pi_{1}\right)=m_{1}+e_{2}
$$

Under the conditions of the first-stage fund benefit of $\pi_{1}$, venture capitalists choose the level of effort, and maximize the utility, namely $\max E\left[\exp \left(-r\left[f_{2}+v_{2}\left(\eta+e_{2}+\varepsilon_{2}\right)-C\left(e_{2}\right)\right]\right) \mid \pi_{1}\right]$

then, $C^{\prime}\left(e_{2}\right)=v_{2}$

It means that the utility is maximized when the expected revenue equals the marginal cost of effort level. The global optimal expected utility function is:

$$
\begin{aligned}
& E\left(U\left(w_{1}, w_{2} ; e_{1}, e_{2}\right)\right)=E\left(-\exp \left(-r\left[\sum_{t=1}^{2} \delta^{t-1}\left[w_{t}-c\left(e_{t}\right)\right]\right)\right)\right. \\
= & r \frac{1}{2}\left[E\left(\pi_{1} \mid e_{1}\right)-C\left(e_{1}\right)\right]+r \delta \frac{1}{2}\left[E\left(\pi_{2} \mid \pi_{1}, e_{1}, e_{2}\right)-C\left(e_{2}\right)\right] \\
= & \frac{r}{2}\left(m_{0}+e_{1}\left(v_{1}\right)-c\left(e_{1}\right)\right)+\frac{r \delta}{2}\left(m_{1}+e_{2}-c\left(e_{2}\right)\right)
\end{aligned}
$$

Maximize the global utility function, namely

$\max _{v_{1}, e_{1}} E U=\frac{r}{2}\left(m_{0}+e_{1}\left(v_{1}\right)-c\left(e_{1}\right)\right)+\frac{r \delta}{2}\left(m_{1}+e_{2}-c\left(e_{2}\right)\right)$

According to the first-order conditions, venture capitalists can get the optimal level of efforts in the first phase of the fund, that is

$$
C^{\prime}\left(e_{1}\right)=\frac{(1-r) \sigma_{0}^{2}+\sigma_{\varepsilon}^{2}}{\sigma_{0}^{2}+\sigma_{\varepsilon}^{2}}
$$

Meanwhile, the results of $v_{1}, v_{2}$ can be obtained.

We can see from $C^{\prime}\left(e_{1}\right), C^{\prime}\left(e_{2}\right)$, the effort levels of venture capitalists are not the same when they are in the different stages of the venture funds. Their effort levels are affected by the financing scale and their capacity before the information of their performance is disclosed, and then affected by the ratio of fund benefit after that.

From the formula (4), (5) and $v_{1}, v_{2}$, the fixed remuneration of venture capitalists can be drawn, namely

$$
\begin{aligned}
& f_{1}\left(v_{1}\right)=\frac{1-2 v_{1}}{2}\left(m_{0}+e_{1}\right)+\frac{1}{2} C\left(e_{1}\right) \\
& f_{2}\left(v_{2}\right)=\frac{1-2 v_{2}}{2}\left[\frac{\sigma_{\varepsilon}{ }^{2} m_{0}+\sigma_{0}^{2}\left(\pi_{1}-e_{1}\right)}{\sigma_{\varepsilon}{ }^{2}+\sigma_{0}^{2}}+e_{2}\right]+\frac{1}{2} C\left(e_{2}\right)
\end{aligned}
$$

As is explained above, the fixed remuneration of the venture capitalists, negatively correlated with the income of the fund $v$, is positively correlated with their levels of effort $e$, and the average ability of their peers $E \eta$. At the same time, the 
differences of all fund managers' ability may also affect the fixed remuneration.

\section{INCENTIVE AND RESTRAINT MECHANISMS FOR THE DEVELOPMENT STAGE FUND}

In the infant period of the second-stage fund, the initial ability and experience of venture capitalists have been increased, and they have a better understanding of themselves. In contrast, the investors know little about some specific information, (which might be carried out by reference to the results of the first-stage fund). We assume that there are two types of venture capitalists, higher skill levels $\eta_{H}$ and lower skill levels $\eta_{L}$. Except for that, other conditions and the fund size are all the same, and then the fund revenue function is

$$
\begin{gathered}
\pi_{\mathrm{H}}=\eta_{\mathrm{H}}+\mathrm{e}+\mathcal{\varepsilon} \\
\pi_{\mathrm{L}}=\eta_{\mathrm{L}}+\mathrm{e}+\varepsilon
\end{gathered}
$$

In order to distinguish the venture capitalists with higher levels, according to Riley separating equilibrium model (Riley, 1979), the optimal contracts between investors and venture capitalists are determined, and they both share the remaining expectations revenue. Therefore, the gains of the venture capitalists with higher levels and the ones with lower levels of are

$$
\begin{aligned}
& f_{H}+v_{H}\left[\eta_{H}+e\left(v_{H}\right)\right]-C\left(e\left(v_{H}\right)\right) \\
&= \frac{1}{2}\left[E\left(\eta_{H}+e\left(v_{H}\right)-C\left(e\left(v_{H}\right)\right)\right)\right] \\
& f_{L}+v_{L}\left[\eta_{L}+e\left(v_{L}\right)\right]-C\left(e\left(v_{L}\right)\right) \\
&= \frac{1}{2}\left[E\left(\eta_{L}+e\left(v_{L}\right)-C\left(e\left(v_{L}\right)\right)\right)\right]
\end{aligned}
$$

The venture capitalists' utility function is

$$
\begin{gathered}
U_{H}=r\left[f_{H}+v_{H}\left[\eta_{H}+e\left(v_{H}\right)+\varepsilon\right]-C\left(e\left(v_{H}\right)\right)\right] \\
U_{L}=r\left[f_{L}+v_{L}\left[\eta_{L}+e\left(v_{L}\right)+\varepsilon\right]-C\left(e\left(v_{L}\right)\right)\right]
\end{gathered}
$$

Maximize the utility function, then the result is obtained by the first-order conditions

$$
v_{H}=C^{\prime}\left(e\left(v_{H}\right)\right)
$$

$$
v_{L}=C^{\prime}\left(e\left(v_{L}\right)\right)
$$

If the efforts of the venture capitalists are the same, namely

$$
C^{\prime}\left(e\left(v_{H}\right)\right)=C^{\prime}\left(e\left(v_{L}\right)\right)
$$

then

$$
v_{H}=v_{L}
$$

Therefore, the profitability residual claims of venture capitalists, both higher level and lower level, are the same when the extents of the efforts of venture capitalists are not fully identified. Being analyzed in the actual situation, the utility function can neither indicate any level of fund benefit nor the efforts of venture capitalists.

Under the above-mentioned conditions, the fixed remuneration of venture capitalists is

$$
\begin{aligned}
& f_{H}=\frac{1}{2}\left[\left(1-2 v_{H}\right)\left[\eta_{H}+e\left(v_{H}\right)\right]+C\left(e\left(v_{H}\right)\right)\right] \\
& f_{L}=\frac{1}{2}\left[\left(1-2 v_{L}\right)\left[\eta_{L}+e\left(v_{L}\right)\right]+C\left(e\left(v_{L}\right)\right)\right]
\end{aligned}
$$

Since $v_{H}=v_{L}=v$, then

$$
f_{H}-f_{L}=\frac{1-2 v}{2}\left(\eta_{H}-\eta_{L}\right)
$$

since $v \leq 1 / 2$, then $f_{H} \geq f_{L}$

Therefore, it can be concluded that the optimal plan of revenue distribution for venture capitalists with different levels is not the claim to the revenue share allocation $\left(v_{H}=v_{L}\right)$, but the differences in management fees $\left(f_{H} \geq f_{L}\right)$.

In the infant stage of the venture fund, since investors learn little about some information, including ability and quality of venture capitalists, venture capitalists work very hard, even in the absence of incentive compensation, to create a higher capital value in order to expand the scale of risk capital and to establish a good reputation (Liu, 2009). At the same time, the venture capitalists with higher levels must be willing to take on more risks in order to distinguish themselves from those with lower levels. They try to deliver some information to investors through remuneration terms. They might even enter into a contract with a zero or a negative-value fixed remuneration, but a very high variable compensation, so that their value is fully aware. The venture capitalists with lower levels are unwilling to bear the risk of failure, thus the fixed remuneration in the contract is emphasized. Under these 
circumstances of information constrained, the skill of venture capitalists is clearly reflected by the contract (Casamatta, 2003). When the venture fund is in the mature stage, venture capitalists with higher lever can obtain a higher fixed remuneration which ensures them more risk compensation.

A design in the different stages of venture fund may provide incentive and restraint mechanisms. Meanwhile, the supplementary terms of the risk compensation and information disclosure system is indispensable arrangements. Only if the legal terms of the risk-benefit compensation are established to control the contract risks, can fund managers use their knowledge and ability more effectively. Moreover, it is benefit for the disclosure of capital management risks and improvement of quality and efficiency of the fund regulation to establish a dynamic supervision and information disclosure system.

\section{REFERENCES}

[1] Casamatta C. "Financing and advising : Optimal financial contracts with venture capitalists, "Journal of Finance, pp.2059-2093, 2003.

[2] Gompers, P. , Lerner, J. "An analysis of compensation in the US venture capital partnership, " Journal of Financial Economic, pp.3-44,1999.

[3] Pingping Liu. Study on the operational mechanism theory of venture capital: Based on contract mechanism and human capital perspective. Beijing: The University of International Business and Economics Press, 2009.

[4] Riley J. "Information equilibrium," Econometrica, pp.331-359, 1979.

[5] Sahlman, W. A. "The structure and governance of venture capital organizations, “ Journal of Financial Economics, pp.473-524, 1990. 